\title{
Fast characterization of compounds and components of explosives
}

\author{
A. Rizzo, C. Telloli ${ }^{\mathrm{a}} \mathbb{1}$, A. Ubaldini, G. Ottaviano, S. Salvi \\ Fusion and Technology for Nuclear Safety and Security Department, Nuclear Safety Security and Sustainability Division, Bologna Research Center, \\ ENEA, via Martiri di Monte Sole 4, 40129 Bologna, Italy
}

Received: 9 January 2021 / Accepted: 19 January 2022

(C) The Author(s) 2022

\begin{abstract}
Finding markers to detect and identify compounds and components related to an explosive is an important task that could reduce threats of unlawful uses of explosives. The capability of Raman spectroscopy to characterize chemical composition of explosive compounds and the analysis of stable isotope ratios could be useful to identify specific markers to identify the origin of the material used. Using Raman spectrometer directly on-site after the accident scene could be a useful tool for an immediate characterization of the components. In addition, carbon and nitrogen analysis on some fragments collected on the accident scene will then confirm the characterization of the components. The proposed configuration of double technique, coupled with a digital database and algorithms, could be useful to run analysis, with fast response time, in work environment related to emergency situations.
\end{abstract}

\section{Introduction}

Explosives have a huge number of useful civil applications, but unfortunately there are also numerous malicious usages connected to the growing threat of terrorism activities. Bomb or explosion-blast debris are likely to be increasingly encountered as terrorist activity increases [1-3].

An explosive is a material, or a mixture of substances, able to produce an explosion using its own energy [4]. All explosives are substances combining oxidizing agent, fuel and initiator $[5,6]$.

Explosives can be divided into three classes based on their reactivity [7]:

- Primary or "triggers" they are highly sensitive to shock, friction, heat or impact; they are unstable material and they are used in the detonator to ignite the secondary explosive [8, 9]. They include triacetone triperoxide [10], styphnate [11, 12], azides [13, 14], fulminate $[15,16]$ and picrate $[17,18]$;

- Secondary or "disruptive" they are more stable than primary explosives and, with a few exceptions, they do not explode by ignition but burn and are much less sensitive to impact, friction and electrostatic charges. Typically, they contain a nitro group for example TNT [19] or nitroglycerin [20];

- Tertiary or "propellants" they are almost insensitive to shock and triggering and to detonate they need secondary charges that amplify the triggering effect of the primary explosives. For example, ammonium nitrate fuel oil (ANFO) [21, 22] and potassium chlorate fuel-oxidizer [23].

Explosives are also categorized as "high-order explosives" or "low-order explosives." The first type is characterized by chemical substances which contain fuel and oxidizer within the same chemical compound. They do not burn but detonate, and they produce a strong supersonic pressure shock wave, for example primary and secondary explosives [24, 25].

The second type, containing for example salts of chlorate or nitrate ions, generally deflagrates and creates a subsonic explosion and lack the high-order explosive blast wave, for example pipe bombs, gun powder and purest petroleum-based bombs using pyrotechnics and propellants.

Therefore, explosives are further characterized based on their chemical source.

Terrorists generally use whatever is available, from illegally obtained manufactured weapons to improvised explosive devices (known as IEDs) that may be composed of high-order explosives or low-order explosives or both [26, 27]. For this reason, finding distinctive markers on the compounds of the explosives is crucial to recognize the sources that could be useful to identify the threat following up the emergency.

A terrorist attack followed by an explosion of IEDs can leave invisible traces of detonated explosives [28, 29]. These traces exist because some parts of explosives may not react to combustion. Therefore, traces of explosives could be thrown into the surrounding environment. The seat of the blast, in fact, will contain explosive residues or bits of the device, which could reveal the original content of the chemical explosive [30,31].

\footnotetext{
a e-mail: chiara.telloli@enea.it (corresponding author)
} 
The first important thing to do after an explosion, related to better understand the chemical composition of the components of the explosive, is to identify the position of the crater which correspond to the area where the bomb was originally placed, in which there are the higher probability to find traces of non-combusted explosive material or its combusted products, or any fragments or material belonging to the IED or on articles affected by the explosion (e.g., soil, buildings, people).

Explosives analysis is very important for homeland security and forensic applications. However, explosives analysis is challenging, and the number of explosive compounds that require monitoring is growing with time. Because modern explosives generally contain different kind of compounds, it is more important to know the source and the amount of the explosive compounds present [32, 33]. Considering that explosive contains more than one compounds, different methodologies have developed over the years [34], but the applied techniques are often destructive, time-consuming and they require a long sample treatment.

Furthermore, the difficulty, if conducting detailed analysis, of complex matrices and the availability of small amounts of the samples taken from the event scene could lead to ambiguous interpretations. A possible solution may come from the combination of rapid on-site techniques, with representative sampling methodologies and tailored off-site techniques in the laboratory and the use of advanced statistical techniques to assess possible matches between material mixtures "after blast" with known materials.

For this reason, it is essential to use innovative techniques that can facilitate the work of researchers by reducing analysis times or using the sample directly without any pre-treatment, for example the ion mobility spectrometry [35, 36] and infrared spectroscopy $[37,38]$.

A rapidly developing spectroscopic technique for detecting traces of explosives is the Raman microscopy that is a powerful technique for identifying post-blast residues [39-42].

Here, we want to focus on the discrimination of the chemical fingerprint of the component of an explosives using a Raman spectrometer directly on-site in the accident scene immediately after the explosion. The principle is that not only the explosive itself should be identified, but also traces of substances that may be added to the explosive or to its precursors.

We have hypothesized a scenario of an illicit explosion and the following request to analyze the debris of the explosion directly on the crime scene. We think that a useful tool to characterize the traces of the unburned components of an explosion in a few minutes could be the Raman spectroscopy using the probe of the instrument [43-45]. We have then simulated to analyze the debris of the exploded bomb directly on-site by Raman instrument.

Subsequently, we have planned to collect representative samples to be analyzed in the laboratory to confirm the data obtained by Raman spectroscopy. Taking into account that same chemical compounds, regardless of their manufacturing process generally exhibit an enough identical chemical composition and sometimes even indistinguishable isotopic $\mathrm{C}, \mathrm{N}$ (and $\mathrm{H}$ ) ratios, some main additive components of the explosives could reveal appreciable difference that could lead to the identification of their origin. We have analyzed the debris off-site using an elementar combustor that is able to analyze macro-samples (in the gram range) with fast response time, and the results allow classifying samples based on the content of $\mathrm{N}$ and $\mathrm{C}$ expressed in \% [46]. Comparing the data obtained with the two instruments (Raman on-site and CN off-site), it is possible to characterize compounds and components of a bomb.

Finally, we have designed an investigation matrix with related advanced statistical tools to enable an expert interrogation of a forensic database to assess the origin of the materials.

\section{Material and methods}

\subsection{Sample description}

Normally, the explosives, regardless of whether they lead to an explosion or a detonation, are characterized by the presence of chemical groups capable of generating effective self-redox reactions. Oxidizing and reducing groups are often both present in the same molecule of the explosive substance, or possibly in the same mixture. Many explosives contain nitrate, chlorate, perchlorate and permanganate groups, which are very rich in oxygen and are therefore strong oxidants. Furthermore, the nitrogen-oxygen bond (in nitrates, nitrogroups and nitroamines) has a lower splitting energy than the bonds between carbon and oxygen, leading to a great gain in terms of chemical transformation.

However, the substances used by criminal groups are often not produced specifically as explosive materials, but they are added with other commonly used materials. The presence of natural compounds in the fragments collected after a blast could give an indication of an explosive of illicit nature, and so homemade crated. An example can be the presence of sucrose mixed with potassium nitrate or an unusual presence of fuel oil mixed with ammonium nitrate.

If each of these substances can be easily analyzed and identified separately, when they are mixed, the analyses are more complex due to the fact that they have often completely different nature and chemical-physical properties. For example, in the Raman spectrum of a mixture of substances one of which exhibits strong fluorescence, the peaks and bands of those of interest can be masked, and they are difficult to recognize. Indeed, also the analysis of not explosive components of an explosive device can be useful for a forensic analysis.

In order to simulate this complexity, different kind of samples were selected as the main components of an explosive and of the debris of a blast (Fig. 1): solid urea, organic fertilizer with equine dejections, two different nitrate-based detergents (detergent_1 was 


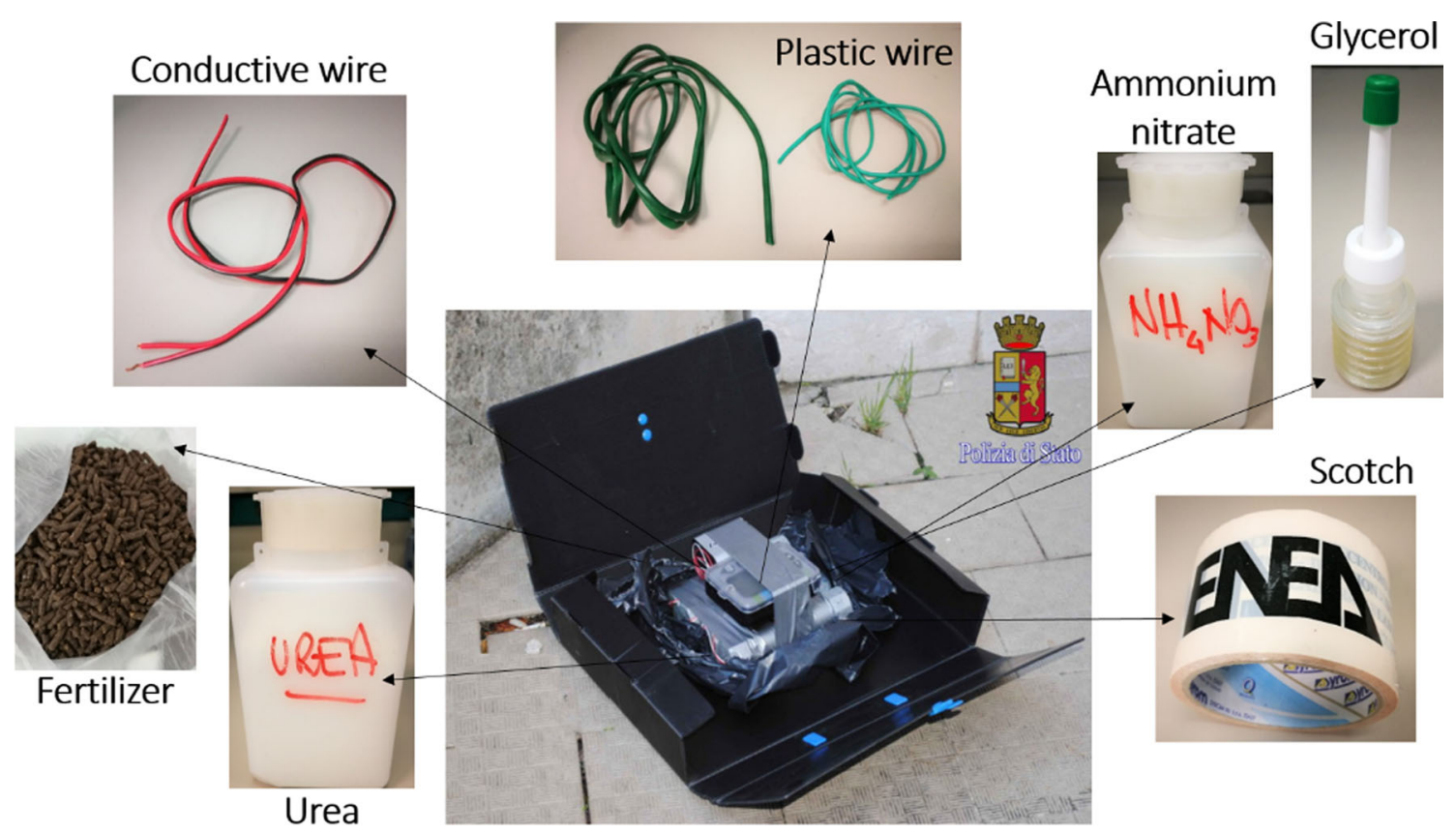

Fig. 1 Images of samples used to simulate the main components of the explosive constituents

liquid, deter-gent_2 was solid), solid ammonia nitrate, two different plasticizers (plasticizer_1 was thin, plasticizer_2 was thick), plasticizer with conductive wire, an example of plastic case and two samples of commercial tape (scotch and Teflon).

We selected these materials, because they contain precursors of explosive constituents [46].

\subsection{Analytical techniques}

Two different kind of analytical techniques have been used for samples analyses: Raman spectroscopy to verify its capability to be used directly on-site on the crime scene and $\mathrm{CN}$ analysis off-site to better characterize the samples already analyzed by through Raman spectroscopy. All the analyses have been performed in the Laboratory of the ENEA research center in Bologna (FSN-SICNUC-TNMT).

Raman spectroscopy is a powerful tool that can be useful in both situations, particularly because it can be used for a very large number of samples, regardless on their physical state and chemical nature. This technique can be applied on solids, crystalline and amorphous materials, polymers, liquids and mixtures. Raman spectroscopy is a vibrational spectroscopic technique. It is widely used in the study of materials, solid, liquid and even gaseous. It is a fast, non-destructive technique that often requires no sample preparation. In the Raman spectroscopy, the radiation emitted by a sample stimulated by a laser, which can be visible, IR or UV, is measured. In the spectrum of diffuse radiation, the components with different energies can be distinguished. Rayleigh radiation represents almost all of it, but having the same energy as the incident radiation, it has negligible use for identification of substances. However, there are also radiations whose energy is different and depend only on the material, so that the obtained signal represents a "chemical footprint" of the substance. In this way, a material can be identified and characterized from the point of view of its chemical-physical properties. In recent years, this technique has also been used in biology and medicine, as well as in material science and in many others fields. In the present work, Raman spectrum of different materials, mixtures or blends were acquired by a BWTEK i-Raman plus spectrometer equipped with a $785 \mathrm{~nm}$ laser. This instrument can be used in combination with a BAC151B video microscope or with a portable Raman probe for in situ analysis. The measurement parameters, acquisition time, number of repetitions, laser energy, have been selected for each sample in order to maximize the signal to noise ratio. For each spectrum, a reference acquisition with the same parameters was previously carried out to subtract the instrumental background.

Elemental analysis of all the samples can reveal the typical composition of the explosive compounds. We used an elemental combustor (Vario Max Cube, Elementar Gmbh, Frankfurt, Germany), based on the Dumas combustion reaction, in order to determine the total carbon and nitrogen content of the samples and its ratio. The elemental combustor is equipped with steel crucibles to avoid the cross-contamination of the samples and to let the recovery of any non-combusted fraction of the sample. The combustion tube was loaded according to manufacturer's specifications with silvered cobaltous/cobaltic oxide, chromium oxide, and quartz wool and operated at $900{ }^{\circ} \mathrm{C}$. The post-combustion tube maintained at $900{ }^{\circ} \mathrm{C}$ was packed with copper oxide, zinc, and quartz wool. The quartz reduction tube, maintained at $830^{\circ} \mathrm{C}$, was packed with reduced copper wire filled between the bottom $40 \mathrm{~mm}$ of the tube and the top $30 \mathrm{~mm}$ of the tube to maintain a high temperature throughout the copper. Resultant water was removed by an anidride trap, and $\mathrm{CO} 2$ gases were trapped in active charcoal column at $40{ }^{\circ} \mathrm{C}$. Adjustable helium $(99,9995 \%$ purity) flux was used 
Table 1 Method selected for $\mathrm{CN}$ analyses and weight used for the different kind of samples

\begin{tabular}{llr}
\hline Sample type & Method & Weight $(\mathrm{mg})$ \\
\hline Ammonium nitrate & Uric acid & 100 \\
Fertilizer & Uric acid & 200 \\
Glycerol & Uric acid & 100 \\
Nitrate solution_1 & Uric acid & 200 \\
Nitrate solution_2 & Uric acid & 200 \\
Urea & Uric acid & 200 \\
Plastic case & Rubber & 20 \\
Scotch & Rubber & 20 \\
Teflon & Rubber & 20 \\
Green wire_1 & Rubber & 20 \\
Green wire_2 & Rubber & 20 \\
Black-red wire & Rubber & 20 \\
\hline
\end{tabular}

as carrier. N2 gases passed through the circuit without being trapped and the thermo-conductivity detector directly measured them. After the N2 analysis has been completed, the trapping column for $\mathrm{CO} 2$ was heated up to $230{ }^{\circ} \mathrm{C}$ to release the adsorbed gas that was then measured by the thermo-conductivity detector [46]. Each different kind of samples were weighed into standard reusable stainless steel crucibles without any pre-treatment, following the different analysis method previous selected and described in Table 1. Regardless the weight, all the samples were analyzed and compared with a reference material consisting of aspartic acid (36\% $\mathrm{C}$, $10 \% \mathrm{~N}$ ), which was used to calculate the daily factor of the instrument and to normalize $\mathrm{C}$ and $\mathrm{N}$ data of the sample to a reference sample.

\subsubsection{Statistical method}

Forensics is a scientific discipline concerning with scientific analysis of physical, biological, behavioral, and documentary evidences in the frame of civil, criminal, or international law. The goal of Forensics is to assess linkages among people, places, things and events. Forensics contributes to the process for identifying the material origin, pathways, or perpetrators associated with an event, relying on the mixture of information from multiple sources, including forensics, law enforcement investigations, and intelligence. The process of identification of the material origin is of paramount importance in case of seizing of illicit explosive materials or in case of explosions due to malevolent acts. Both seized illicit explosive materials and debris from an explosion should be analyzed in a laboratory, and then they should be compared with a database of known explosive materials (this could be a National Explosives Forensic Library) in order to search for a possible match. Such a database could include all type of known explosives and their precursors and also materials suitable to be used as explosive shell. The search for a possible match is possible using the following method:

1. Observations matrix Arrange the database in a mxn matrix in which the $\mathrm{m}$ rows are the observations and the $\mathrm{n}$ columns are the characteristic parameters for each observation. The columns are the $\mathrm{n}$ elements of the parameter vector $\mathrm{P}$ of the observations (Fig. 2a). Each observable is a point in the n-dimensional space of the parameters $\mathrm{S}_{\mathrm{p}}$.

2. Vector $P_{u}$ of useful parameters Select a parameters vector $P_{u}=\left[P_{1}, P_{3}, P_{6}, \ldots, P_{q}\right](q \leq n)$ with the parameters useful to assess the possible match. If the dimension $n$ of the space $S_{p}$ is small, the identification of the useful parameters is possible based on the researcher's expertise. If the dimension $n$ of the space $S_{p}$ is quite large ( $\left.n \geq 30\right)$, it could be useful to reduce the dimension finding the most significant variables through advanced statistical techniques like, for example, a principal component analysis.

3. Investigation matrix The application of the $P_{u}$ vector to the observation matrix will result in an investigation matrix mxq $(q$ $\leq n$ ) (Fig. 2b). The $\mathrm{P}_{\mathrm{u}}$ vector should be also applied both to the seized-explosive and the explosion-debris. Then the possible match between the seized-explosive/explosion-debris and the library could be assessed using a chromatic code: Green $=$ positive match; Red = negative match; White = impossible match (Fig. 2c).

4. Result matrix Excluding observations with at least one red value, the investigation matrix is reduced to a result matrix rxs ( $r$ $\leq m ; s \leq n)$ (Fig. 2d).

Most likely, not all the observations will have all green fields, and therefore it will be possible to assess a match percentage between the library and the seized-explosive/explosion-debris. 
Fig. 2 Database for searching a possible match: a observation matrix $\mathrm{mxn}$; $\mathbf{b}$ investigation matrix mxq; c chromatic code applied to the investigation matrix; $\mathbf{d}$ result matrix

\begin{tabular}{|c|c|c|c|c|c|c|}
\hline \multicolumn{7}{|c|}{ PARAMETER MATRIX } \\
\hline & Parameter 1 & Parameter 2 & $\ldots$ & $\ldots$ & $\ldots$ & Parameter $\mathrm{n}$ \\
\hline \multicolumn{7}{|l|}{ Observation 1} \\
\hline \multicolumn{7}{|l|}{ Observation 2} \\
\hline \multicolumn{7}{|l|}{$\ldots$} \\
\hline \multicolumn{7}{|l|}{$\ldots$} \\
\hline$\ldots$ & & & & & & \\
\hline Observation $\mathrm{m}$ & & & & & & \\
\hline
\end{tabular}

\begin{tabular}{|c|c|c|c|c|c|c}
\hline \multicolumn{7}{|c}{ INVESTIGATION MATRIX } \\
\hline & P1 & P3 & P6 & $\ldots$ & $\ldots$ & Pq \\
\hline Observation 1 & & & & & & \\
\hline Observation 2 & & & & & & \\
\hline$\ldots$ & & & & & & \\
\hline$\ldots$ & & & & & & \\
\hline$\ldots$ & & & & & & \\
\hline Observation m & & & & & & \\
\hline
\end{tabular}

\begin{tabular}{|c|c|c|c|c|c|c}
\hline \multicolumn{7}{|c|}{ INVESTIGATION MATRIX } \\
\hline & P1 & P3 & P6 & $\ldots$ & $\ldots$ & Pq \\
\hline Observation 1 & & & & & & \\
\hline Observation 2 & & & & & & \\
\hline$\ldots$ & & & & & & \\
\hline$\ldots$ & & & & & & \\
\hline$\ldots$ & & & & & & \\
\hline Observation m & & & & & & \\
(c)
\end{tabular}

INVESTIGATION MATRIX

\begin{tabular}{|c|c|c|c|}
\hline & P3 & $\ldots$ & $\ldots$ \\
\hline Observation 1 & & & \\
\hline Observation 2 & & & \\
\hline$\ldots$ & & & \\
\hline$\ldots$ & & & \\
\hline$\ldots$ & & & \\
\hline Observation m & & & \\
\hline
\end{tabular}

(d)

\section{Results}

\subsection{Raman data results}

The Raman spectra of pure ammonium nitrate (curve blue "A"), of potassium nitrate (curve orange "B") and of physical mixture of these salts, formed by about the $40 \%$ of the former and obtained by finely grinding their powders (curve green " $\mathrm{C}$ "), are shown in Fig. 3. The curves are scaled along the ordinate axis by a constant for reasons of clarity.

Despite some chemical analogies, these two nitrates have different crystalline structure, so it is not surprising that the main bands are in similar but still well-distinct spectral positions. The peaks are well-distinct even in the case of a mixture (curve green "C"). Their relative intensity depends on their initial ratio, but not the absolute position in terms of Raman shift. This means that the Raman spectroscopy technique has the potential to recognize the presence of explosive substances, even when they are mixed with others.

As regard the additives, the spectra of ammonium nitrate compared with some additives and their parent materials have been collected (Fig. 4). The curves show the spectra of ammonium nitrate (A), of the mixtures of this salt with $2 \%$ glycerol (B) and with charcoal $(C)$ and of pure glycerol (D) and of isolated charcoal (E), respectively.

The mixture between ammonium nitrate and fuel oil is a powerful and widely used industrial explosive, known commercially by the name of ANFO (which is made up of approximately $94 \%$ of the inorganic compounds). As the exact composition can be difficult to prepare in an artisanal way, a homemade mixture will exhibit anomalous relative percentages of the inorganic and organic 
Fig. 3 Raman spectra of NH4NO3 (blue curve "A"), KNO3 (orange curve "B") and of their physical mixture (green curve " $\mathrm{C}$ "); the inset shows the part of the spectra close to their most intense bands, around $1050 \mathrm{~cm}^{-1}$

Fig. 4 Raman spectra of NH4NO3 (curve light blue "A"), NH4NO3 mixed with about $2 \%$ of glycerol (curve orange "B"), with charcoal (curve yellow " $\mathrm{C}$ "), of pure glycerol (curve gray "D") and of isolated charcoal (curve blue "E")
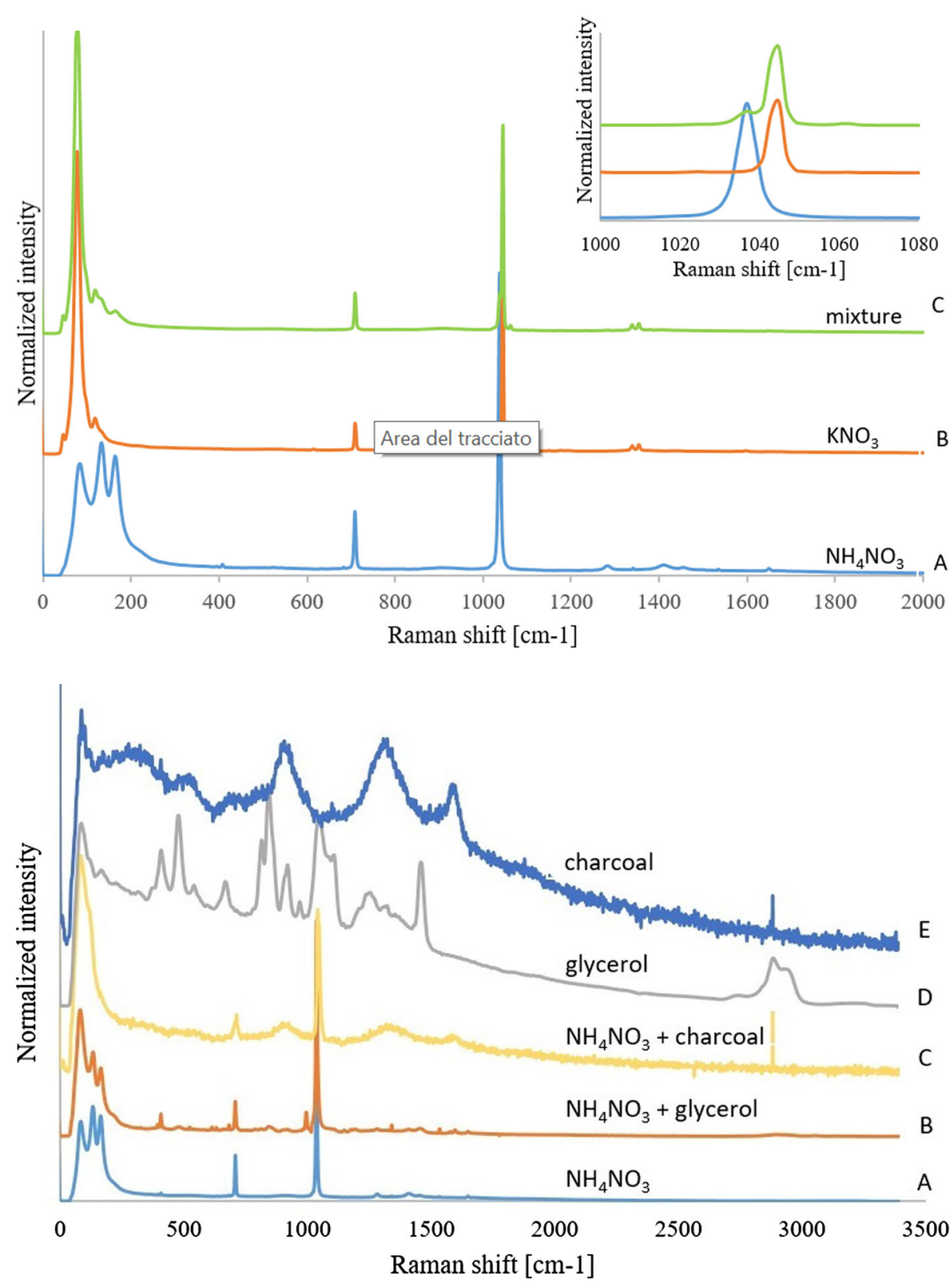

components, suggesting a malicious intention in the fabrication of the material. Also the presence of other organic compounds than fuel, may be suspicious as well.

When a Raman spectroscopy analysis is run on these mixtures, the relative bands due to the organic components, although weak, are easily recognized and are quite indicative. Signals around $3000 \mathrm{~cm}^{-1}$ indicate the presence of carbon-hydrogen bonds that cannot be related to the inorganic part.

In the case of ammonium/nitrate charcoal, the mixture was prepared mixing vigorously powders of the two compounds in an agate mortar with a large excess of coal, in order to simulate the intent to hide the explosive material.

It is interesting to note that the vegetable carbon excited by the laser shows a fluorescence that can also be noticed in the spectrum of the mixture, which shows a weak humpiness even where there are no evident peaks.

In the case of a forensic analysis, it may be necessary to recognize the different parts of an improvised explosive device, without necessarily being able to identify with absolute precision the material they are made of. An improvised device is often formed by a container, usually plastic, inside which there are electrical cables, adhesive tapes and other components.

Raman spectra of some plastic cases easily available on the market are shown in Fig. 5a. The great difference with a typical inorganic substance is evident, as the number of bands is much greater, and there is some additional fluorescence. Similar observations and results can be found when different electrical cables (Fig. 5b) and different tapes (Fig. 5c) are analyzed; even in these cases, the forensic investigation may make use of the Raman spectroscopy as a reliable and fast on-site tool. 
Fig. 5 Raman spectra related to: a three different plastic cases;

b some electric cables;

c commercial tapes

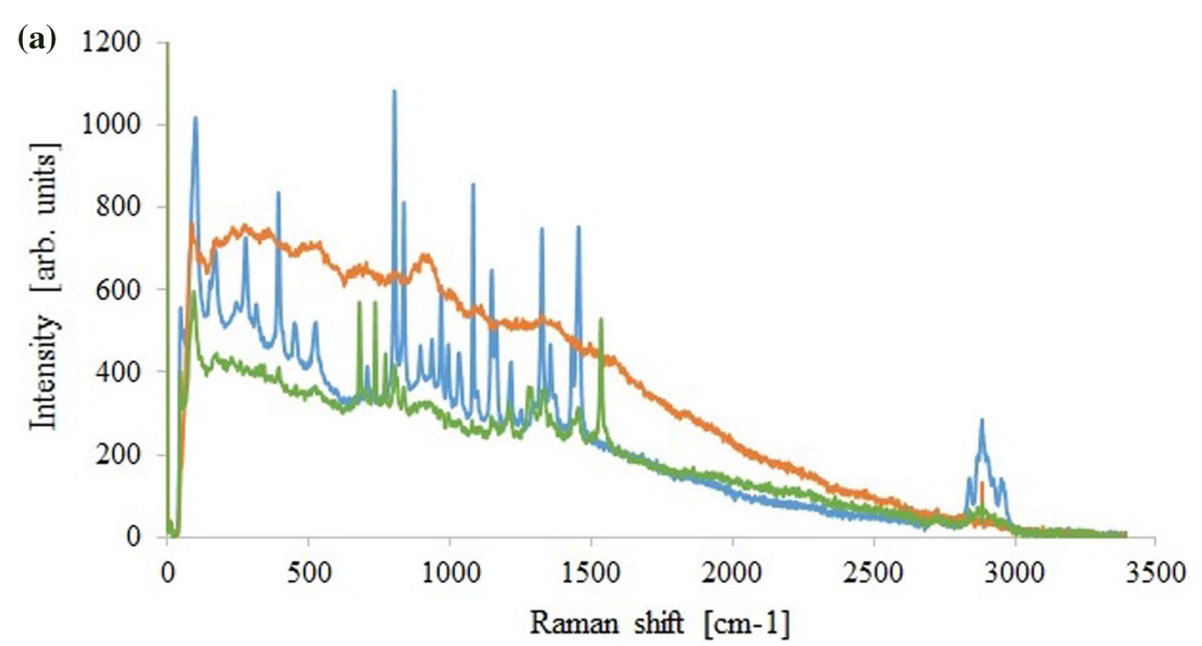

- plastic case $1 \longrightarrow$ plastic case $2-$ Plastic case 3
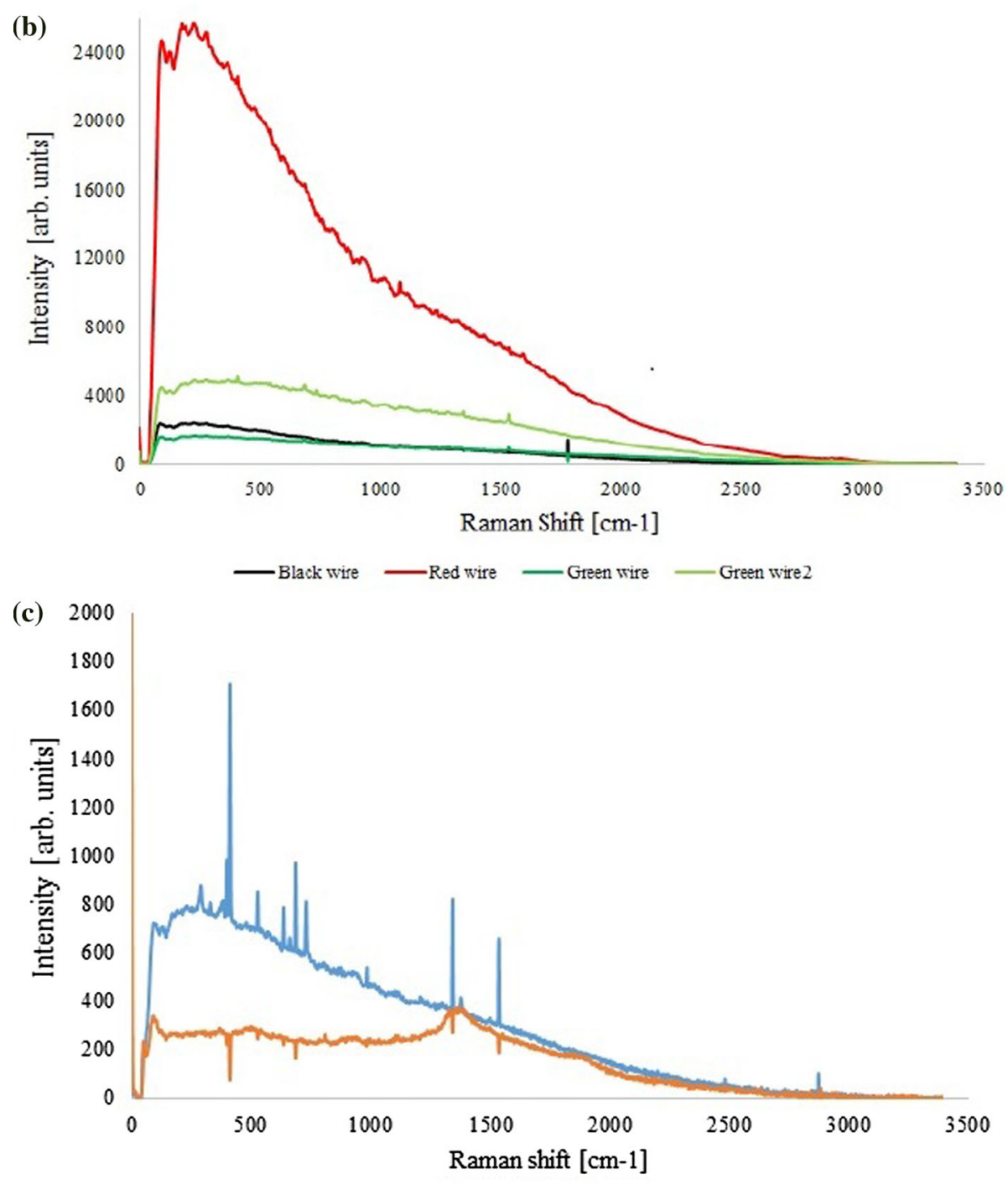
Table 2 Average and standard deviation (STD) of carbon (C) and nitrogen (N) content of each samples analyzed

\begin{tabular}{|c|c|c|c|c|}
\hline \multirow[t]{2}{*}{ Sample type } & \multicolumn{2}{|l|}{$\mathrm{N}(\%)$} & \multicolumn{2}{|l|}{$\mathrm{C}(\%)$} \\
\hline & Average & STD & Average & STD \\
\hline Ammonium nitrate & 37.93 & 7.96 & 0.22 & 0.41 \\
\hline Urea & 57.52 & 9.02 & 20.17 & 0.04 \\
\hline Fertilizer & 22.34 & 2.43 & 36.73 & 0.29 \\
\hline Nitrate sol_1 & 1.01 & 0.00 & 2.97 & 0.15 \\
\hline Nitrate sol_2 & 2.15 & 0.02 & 5.67 & 8.70 \\
\hline Glycerol & 0.03 & 0.02 & 31.44 & 1.16 \\
\hline Green wire & 0.07 & 0.07 & 45.61 & 0.86 \\
\hline Green wire_2 & 0.04 & 0.01 & 48.67 & 0.61 \\
\hline Black-red wire & 0.00 & 0.01 & 24.80 & 1.10 \\
\hline Teflon & 0.08 & 0.06 & 85.25 & 0.34 \\
\hline Scotch & 0.32 & 0.16 & 87.11 & 6.54 \\
\hline Scotch + am.ni & 16.76 & 4.30 & 45.47 & 6.09 \\
\hline Plastic case & 0.02 & 0.00 & 92.04 & 0.22 \\
\hline
\end{tabular}

\section{2 $\mathrm{CN}$ data results}

Each sample was analyzed three times to gain some statistic. The average values and absolute standard deviations are given below. The results show that the all the samples can be analyzed with a very high precision.

Table 2 displays the concentrations of carbon $(\mathrm{C})$ and nitrogen $(\mathrm{N})$ for each samples, expressed as the average percentage of the analyses performed and the relative standard deviation for both nitrogen and carbon content.

Urea shows the highest concentration of $\mathrm{N}$ compared to the other; instead of plastic case that shows the highest concentration of $\mathrm{C}$ followed by Teflon and scotch tape.

Figure 6 shows the nitrogen and carbon content expressed in percentage in all analyzed samples (Figs. 6a, c respectively). Except for ammonium nitrate and urea, all the other samples have shown very small amount of nitrogen. Excluding the samples with high nitrogen content, it is possible to note that this instrument is able to discriminate the samples with a very small amount of nitrogen content (less than 0.1\%), as shows in Fig. 6b. On the other side, the concentration in percentage of carbon is different among all samples. Except ammonium nitrate and the two nitrate solutions, the other samples show the presence of carbon in a range between 20 and $90 \%$.

In detail, Fig. 7 shows two different histograms on the carbon content (Fig. 7a) and nitrogen content (Fig. 7b) in the samples representing the plastic parts of the possible hand-made bomb: green and thin wire, green and thick wire, black and red conductive wire, Teflon tape and scotch tape. Teflon and scotch show the highest concentration of both carbon and nitrogen respect to the other wire samples, despite the value percentage differed by two units, from $0.32 \%$ of $\mathrm{N}$ to $87 \%$ of $\mathrm{C}$ in scotch sample and from $0.08 \%$ of $\mathrm{N}$ to $85 \%$ of $\mathrm{C}$ in Teflon sample. The difference related to the thickness of the two green wire samples is negligible, as well as the value obtained on the black-red conductive wire. In this last case, probably the decrease in value of both $\mathrm{C}$ and $\mathrm{N}$, could be related to the presence of the copper wire inside the plastic wire colored in black and red which was not burned by the instrument.

Then, we have tried to smear a small piece of scotch with ammonium nitrate and we analyzed it. The data obtained are shown in Figs. 7c for $\mathrm{C}$ content and $7 \mathrm{~d}$ for $\mathrm{N}$ content. As expected, the instrument reveals small parts of ammonium nitrate which shows a much higher peak concentration in percentage than the sample without ammonium nitrate.

Figure 8 shows the results related to $\mathrm{C}$ and $\mathrm{N}$ content in urea, fertilizer and glycerol samples. Urea shows high nitrogen content respect to glycerol in which the $\mathrm{N}$ value is the shortest.

\section{Discussion}

The goal of this research is to try to trace the used materials back to their origin, analyzing the fragments of the components used to build the blast, not the additive, but only the solid components. Analyzing the fragments of the components that characterize the blast, it is possible to recognize the presence of very small quantity of the additive used that have remained on the components of the blast. Figure 1 shows a possible blast that could be built with plasticizers, commercial tape (scotch and Teflon) and bag / suitcase. We hypothesize to analyze the fragment of this compounds to characterize the presence of, for example, urea, organic fertilizer, nitrate-based detergents or ammonia nitrate. 

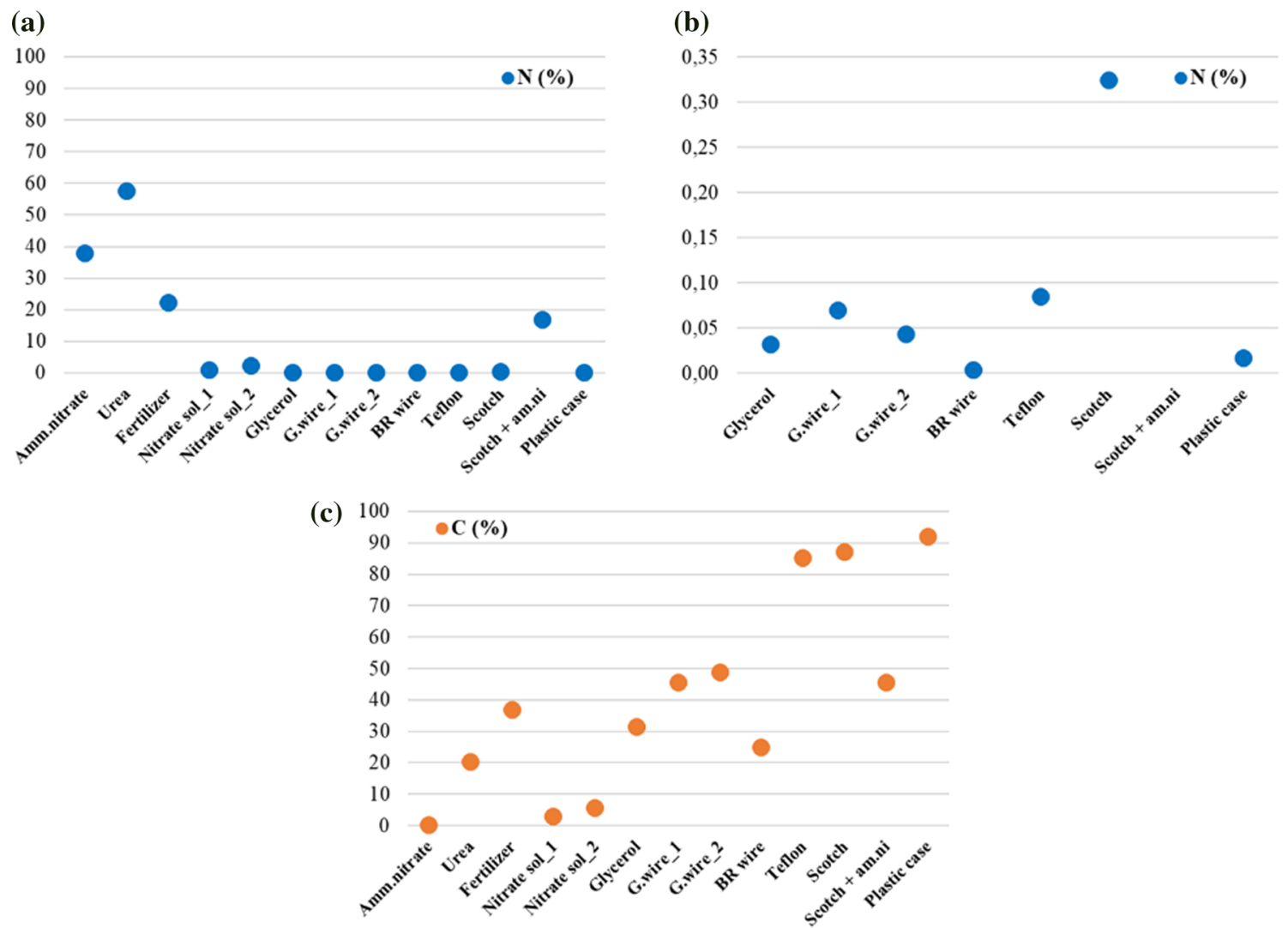

Fig. 6 Nitrogen and carbon content expressed in percentage and analyzed by CN Vario Max Cube in all the samples: a nitrogen graphic in blue; b nitrogen graphic excluded the samples with high concentration of nitrogen in blue; $\mathbf{c}$ carbon graphic in orange

The Raman spectroscopy technique has the potential to recognize the presence of explosive substances, even when they are mixed with others. This is of great importance, because criminal groups often use additives to increase the explosive properties of commonly used materials or with the intent of hiding the explosive component and to make the identification more difficult. Their presence strongly indicates illegal use. In the case of a forensic analysis, it may be necessary to recognize the different parts of an improvised explosive device, without necessarily being able to identify with absolute precision the material they are made of. The great advantage of Raman spectroscopy is its capability to quickly recognize the macro categories of materials (plastics, charcoal, cabling, organic, inorganic). A portable Raman spectrometer can be utilized for a rapid in situ test, allowing the identification of compounds related to a denotation, which can then be analyzed later more thoroughly in a specialized laboratory.

The instrument $\mathrm{CN}$ Vario Max Cube resolved samples with different $\mathrm{C}$ and $\mathrm{N}$ content in a few minutes, discriminating them from each other and it is able to analyze macro samples in the gram range with fast response time. This instrument is used to better analyze the fragments of the solid compounds that could be found in the form of coarse fragments and so of the order of the weight of grams. The results of the analysis allow classifying samples based on the content of nitrogen and carbon expressed in percentage (as previously shown in Rizzo et al. [46].

\section{Conclusions}

The double approach, on-site and off-site analyses, has been proved to provide fast and reliable results supporting the investigation process of an unknown explosion, in work environment related to emergency situations. The use of the probe of the laser spectrometer allows efficient collection of Raman spectra of debris with very simple preparation of the sample.

The content of $\mathrm{C}$ and $\mathrm{N}$ is distinctive markers characterizing improvised and homemade explosives precursors that could be detected in the bombing accident scene. 
(a)

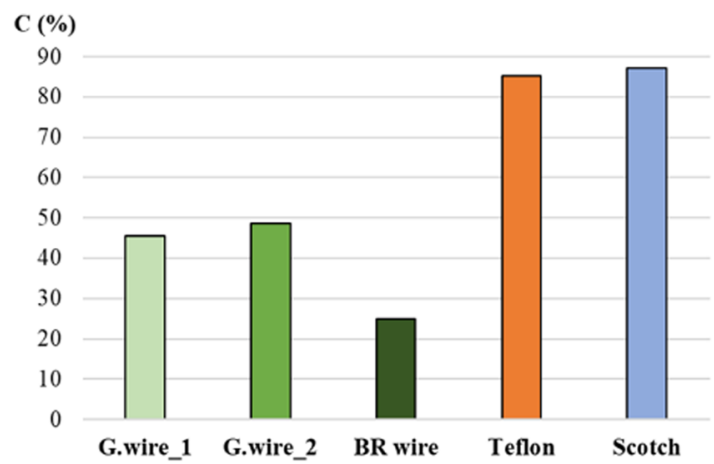

(c)
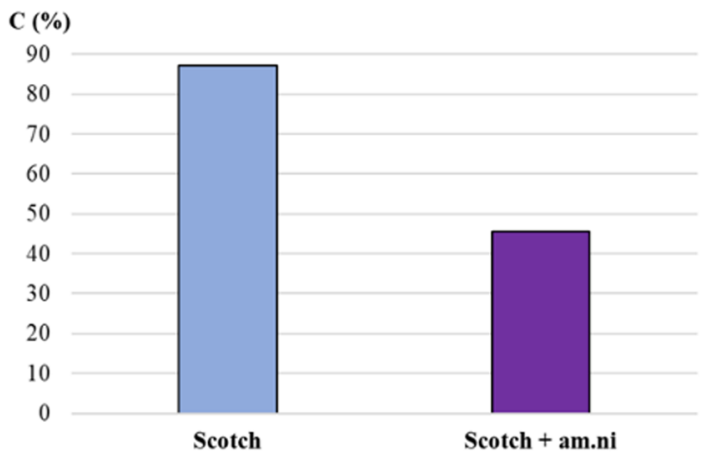

(b)

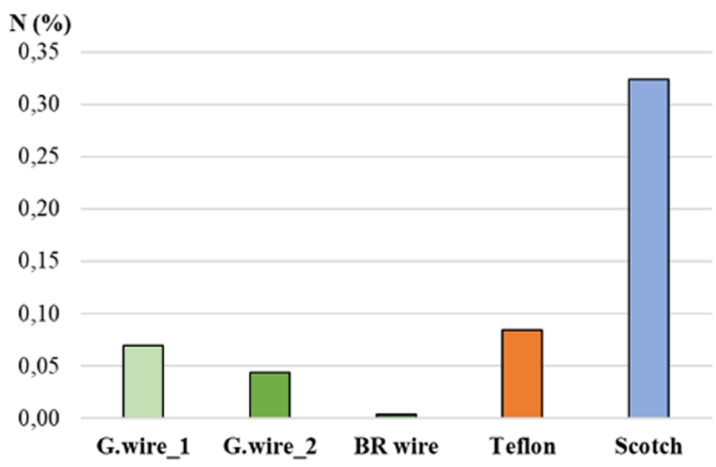

(d)

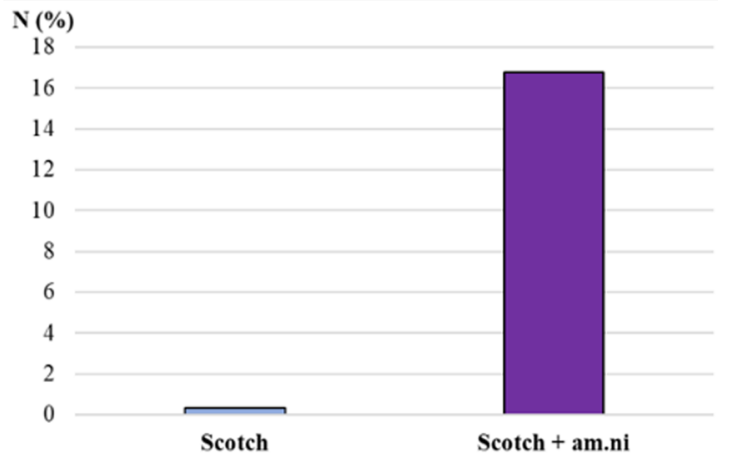

Fig. 7 Histogram related to nitrogen and carbon concentration expressed in percentage and analyzed by CN Vario Max Cube in the plasticizer samples: $\mathbf{a}$ carbon value; $\mathbf{b}$ nitrogen value; $\mathbf{c}$ carbon value in the detailed samples of scotch (in blue) and scotch with ammonium nitrate (in purple); $\mathbf{d}$ nitrogen value in the detailed samples of scotch (in blue) and scotch with ammonium nitrate (in purple)

Fig. 8 Nitrogen and carbon content expressed in percentage and analyzed by $\mathrm{CN}$ Vario Max Cube in three samples (uric acid, fertilizer and glycerol); the orange symbols represented the value of carbon content and the blue ones the nitrogen content

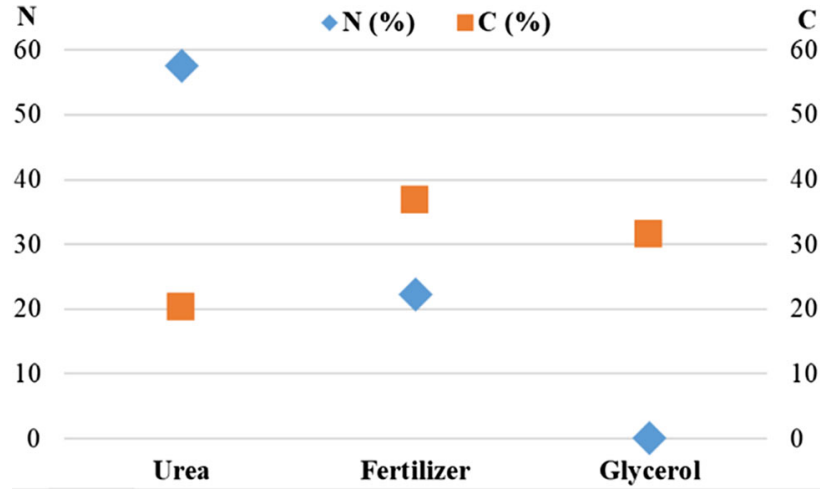

The creation of a digital database is very important in order to assess the possible match between known samples and seizedexplosive/explosion-debris, using suitable algorithms and advanced statistical techniques.

Open Access This article is licensed under a Creative Commons Attribution 4.0 International License, which permits use, sharing, adaptation, distribution and reproduction in any medium or format, as long as you give appropriate credit to the original author(s) and the source, provide a link to the Creative Commons licence, and indicate if changes were made. The images or other third party material in this article are included in the article's Creative Commons licence, unless indicated otherwise in a credit line to the material. If material is not included in the article's Creative Commons licence and your intended use is not permitted by statutory regulation or exceeds the permitted use, you will need to obtain permission directly from the copyright holder. To view a copy of this licence, visit http://creativecommons.org/licenses/by/4.0/. 


\section{References}

1. C.C. Combs, M.W. Slann, Encyclopedia of terrorism (Facts on file library of world history), 2nd edn. (Facts on File, New York, 2007)

2. J.M. Hanhimaki, B. Blumenau, An international history of terrorism: western and non-western experiences (Routledge, London, 2013)

3. J.M. Lutz, B.J. Lutz, Global terrorism (Routledge, London, 2013)

4. S. Gawande, Int. J. Energ. Mater. 3(1), 11-18 (2017)

5. W.G. Proud, J. R. Army Med. Corps 159(Supp 1), i4-9 (2013)

6. R. Meyer, J. Köhler, A. Homburg, Explosives, 7nd edn. (John Wiley \& Sons, 2016)

7. J. Akhavan, The chemistry of explosives, 3nd edn. (RSC Publishing, 2015)

8. S. Parajuli, W. Miao, Anal. Chem. (2013). https://doi.org/10.1021/ac401962b

9. L. Barron, E. Gilchrist, Anal. Chim. Acta (2014). https://doi.org/10.1016/j.aca.2013.10.047

10. A. Crowson, R. Cawthorne, Sci. Justice 52(4), 217-25 (2012). https://doi.org/10.1016/j.scijus.2012.07.001

11. R. Matyáš, J. Šelešovský, T. Musil, J. Hazard Mater 213-214, 236-41 (2012). https://doi.org/10.1016/j.jhazmat.2012.01.085

12. F. Ji, H. Yin, H. Zhang, Y. Zhang, B. Lai, J. Clean. Prod. (2018). https://doi.org/10.1016/j.jclepro.2018.04.029

13. N. Mehta, K. Oyler, G. Cheng, A. Shah, J. Marin, K. Yee, Z. Anorg. Allg. Chem. (2014). https://doi.org/10.1002/zaac.201400053

14. J.G. Xu, C. Sun, M.J. Zhang, B.W. Liu, X.Z. Li, J. Lu, S.H. Wang, F.K. Zheng, G.C. Guo, Chem. Mater. (2017). https://doi.org/10.1021/acs.chemmater. $7 \mathrm{~b} 03453$

15. B. Khasainov, M. Comet, B. Veyssiere, D. Spitzer, Prop. Explos. Pyrotech. (2017). https://doi.org/10.1002/prep.201600181

16. W.R. Martin, D.W. Ball, J. Energ. Mater. (2019). https://doi.org/10.1080/07370652.2018.1531089

17. X. Tan, Y. Fan, S. Wang, Y. Wu, W. Shi, T. Huang, G. Zhao, Electrochim Acta (2020). https://doi.org/10.1016/j.electacta.2020.135706

18. B.C. Tappan, J.M. Budzinski, E.M. Mas, L.M. Hull, L.G. Hill, P.R. Bowden, J.P. Lichthardt, A.M. Schmalzer, M. Shorty, P.I. Miller, D.L. McDonald, M.W. Burkett, AIP Conf. Proc. (2020). https://doi.org/10.1063/12.0000917

19. R. Tu, B. Liu, Z. Wang, D. Gao, F. Wang, Q. Fang, Z. Zhang, Anal. Chem. (2008). https://doi.org/10.1021/ac800060f

20. H. Grau, A.Y. Fadeev, J. Colloid Interface Sci. (2019). https://doi.org/10.1016/j.jcis.2019.03.063

21. S.I. Jackson, P. Combust. Inst. (2017). https://doi.org/10.1016/j.proci.2016.09.027

22. A. Biessikirski, M. Pytlik, L. Kuterasiński, M. Dworzak, M. Twardosz, B.D. Napruszewska, Energies (2020). https://doi.org/10.3390/en13153763

23. J.M. Crespo Cajigas, L.P. Almodovar, L.E. DeGreeff, Talanta (2019). https://doi.org/10.1016/j.talanta.2019.120127

24. B.M. Dobratz, Technical report United States (1981), Available online at: https://www.osti.gov/biblio/6530310

25. T.E. Scott, E. Kirkamn, M. Haque, I.E. Gibb, P. Mahoney, J.G. Hardman, Br. J. Anaesth. (2017). https://doi.org/10.1093/bja/aew385

26. A. Ramasamy, A. Hill, J. Clasper, BMJ Military Health (2009). https://doi.org/10.1136/jramc-155-04-05

27. J. Grove, Int. Political Sociol. (2016). https://doi.org/10.1093/ips/olw018

28. R.R. Kunz, K.C. Gregory, D. Hardy, J. Oyler, S.A. Ostazeski, A.W. Fountain III., Anal. Bioanal. Chem. (2009). https://doi.org/10.1007/s00216-0092748-2

29. N. Vanderheyden, E. Verhoeven, S. Vermeulen, B. Bekaert, Sci. Rep. (2020). https://doi.org/10.1038/s41598-020-69385-1

30. D. Fisher, R. Zach, Y. Matana, P. Elia, S. Shustack, Y. Sharon, Y. Zeiri, Talanta 174, 92-99 (2017). https://doi.org/10.1016/j.talanta.2017.05.085

31. T.P. Forbes, S.T. Krauss, G. Gillen, Trends Analyt. Chem. (2020). https://doi.org/10.1016/j.trac.2020.116023

32. C. Cruces-Blanco, L. Gámiz-Gracia, M. García-Campaña, Trends Analyt. Chem. (2007). https://doi.org/10.1016/j.trac.2006.12.007

33. M.A.F. Fernández de la Ossa, M. López-López, M. Torre, C. García-Ruiz, Trends Analyt. Chem. (2011). https://doi.org/10.1016/j.trac.2011.06.014

34. D.J. Klapec, G. Czarnopys, J. Pannuto, Forensic Sci. Int. Synergy (2020). https://doi.org/10.1016/j.fsisyn.2020.01.020

35. M. Amo-González, S. Pérez, R. Delgado, G. Arranz, I. Carnicero, Anal. Chem. (2019). https://doi.org/10.1021/acs.analchem.9b03589

36. G.R. Asbury, J. Klasmeier, H.H. Hill Jr., Talanta (2000). https://doi.org/10.1016/S0039-9140(99)00241-6

37. C.J. Breshike, C.A. Kendziora, R. Furstenberg, V. Nguyen, R.A. McGill, Proceedings CBRNE Sensing XVIII (2017) Doi: https://doi.org/10.1117/12. 2262199

38. T.P. Forbes, E. Sisco, M. Staymates, Anal. Chem. (2018). https://doi.org/10.1021/acs.analchem.8b01037

39. H. Wackerbarth, C. Salb, L. Gundrum, M. Niederkrüger, K. Christou, Appl. Opt. (2010). https://doi.org/10.1364/AO.49.004362

40. M.E. Farrell, E.L. Holthoff, P.M. Pellegrino, in Proceedings Detection and Sensing of Mines, Explosive Objects and Obscured Targets (2015) Doi: https://doi.org/10.1117/12.2176553

41. F. Zapata, M.A.F. Fernández de la Ossa, E. Gilchrist, L. Barron, C. García-Ruiz, Talanta (2016). https://doi.org/10.1016/j.talanta.2016.05.057

42. D. Videira-Quintela, F. Zapata, C. García-Ruiz, J. Raman Spectrosc. (2018). https://doi.org/10.1002/jrs.5455

43. Y. Shi, W. Wang, J. Zhan, Nano Res. (2016). https://doi.org/10.1007/s12274-016-1135-5

44. N. Chen, P. Ding, Y. Shi, T. Jin, Y. Su, H. Wang, Y. He, Anal. Chem. (2017). https://doi.org/10.1021/acs.analchem.7b00521

45. R. Gillibert, J.Q. Huang, Y. Zhang, W.L. Fu, M.L. de la Chapelle, Trends Anal. Chem. (2018). https://doi.org/10.1016/j.trac.2018.03.018

46. A. Rizzo, C. Telloli, P. Bartolomei, F. Manassero, Eur. Phys. J. Plus (2018). https://doi.org/10.1140/epjp/i2018-12151-6 